\title{
Socio-cultural Factors Influencing Out-of-class English Learning: A Case Study of First-year University Students in China
}

\author{
Xianbin $\mathrm{Ji}^{*} \quad$ Janpanit Surasin Denchai Prabjandee \\ Faculty of Education, Burapha University 169 LongHad Bangsaen Rd, Chon Buri 20131, Thailand \\ * E-mail of the corresponding author: ji-xianbin@hotmail.com
}

\begin{abstract}
Out-of-class English learning is important for second language development. Previous studies have explored the types of out-of-class activities learners were engaged in, but the factors influencing learners to do those activities remain scarce, especially in the Chinese context. This study aimed to investigate the socio-cultural factors influencing Chinese students' out-of-class English learning. Case study research was used to collect the qualitative data from the interview of twenty Chinese first-year undergraduate students, and observation was used to supplement the data. The data were analyzed vertically (within-case) and horizontally (cross-case). The findings revealed that the socio-cultural factors influencing out-of-class learning were as follows: peers, benefits, environment and activities.
\end{abstract}

Keywords: out-of-class English learning; socio-cultural factors

DOI: $10.7176 / \mathrm{JEP} / 11-32-02$

Publication date: November $30^{\text {th }} 2020$

\section{Introduction}

This study is based on the socio-cultural theory of Vygotsky (1978). It aims at investigating socio-cultural factors influencing out-of-class English learning. Out-of-class learning plays a significant role in language learning (Inozu, Sahinkarakas \&Yumru, 2010; Pearson, 2004). It has been highlighted that English language learning is not only limited to classroom contexts, but can also be done at any place, any time, and with any resource ((Benson \& Reinders, 2011; Hyland, 2004; Pearson, 2004). In a globalized world with a vast multiplicity of resources, access to English learning material has become common. Moreover, Field (2007) explained that in order to enhance English language competence, learners need to develop the ability to acquire English skill that are available both inside and outside the classroom context. Therefore, it is also essential for teachers to promote and support students' English learning outside the classroom by offering a flexible learning scheme and resources.

Although the aforementioned studies provided significant insight concerning the nature of activities students carried out, little is known about what and how the factors drive the learners to do those activities. Moreover, with the rapid development of society, the factors influencing learners' out-of-class English learning may different from last decade. It is little understood now that what and how socio-cultural factors influencing Chinese students' outof-class English learning.

In the Chinese English learning context, particularly in secondary schools, English language teaching in China is often reported as being heavily exam and grammar oriented (Butler, 2011; Pan \& Block, 2011), with grammar exercises, translation and filling in worksheets being the most frequent activities in English classes (Song, 2013). Students can hardly ever practice English or join English activities outside the classroom. Although most of students worked hard in class, due to lack of English practices outside the classroom, their learning efficiency got restricted. The exam-driven English learning in China creates negative impact on language learning (Kirkpatrick \& Zang, 2011). Chinese students still lack out-of-class English learning experiences, what socio-cultural factors and how they influence Chinese university students' out-of-class English learning is meaningful and it is a new research area to explore.

Out-of-class English learning refers to English learning activities outside the classroom conducted by learners independently.

Socio-cultural factor is defined as significant "others" influence learner's English learning. These factors are the external factors on the social level which may impact the motivation, autonomy, and attitude of language learning. First year university students in China are students at Faculty of International School. They were purposefully selected to participate in this study.

\section{The Present Study}

2.1 Research question

How do these socio-cultural factors influence first-year undergraduate Chinese students to participate in out-ofclass English learning?

\subsection{Context and participants}

This study was conducted in a university in China. The unit of analysis in this study was out-of-class English 
learning experience, bounded with 20 first-year undergraduate students in China. I got the approval letter from the principal of International School in Kunming University of Science and Technology. Then I went to the clubs for several times as a non-participant observer. Most of the participants in the English clubs were from the same faculty and they all are year one students. The participants I selected were from the English club, they also had other experiences of out-of-class English learning activities. What's more, the participants I selected have good English proficiency, they could express their perspectives in English well.

\subsection{Data collection}

To elicit the data, the participants were interviewed one by one at the end of the out-of-class English activities. Twenty in-depth participant interviews were conducted to find the factors that contributed to the students' English use outside the classroom. I relied on their memories to recount their experiences during joining the English club. Each interview followed the same protocol (see Appendix A). All interviews were conducted by the first researcher during the first semester of the first year. The interviews were conducted face to face in a comfortable, relaxed, and undisturbed environment, and lasted between 25 and $45 \mathrm{~min}$. All of the interviews were recorded and fully transcribed.

Apart from the interview, I also conducted two shadowing observations of different tpyes of English clubs and two shadowing observasion about the participant's out-of-class English learning experience and sketched the contexts for analysis (Wolcott, 2003). The total period of observations across the English club and two participants was 18 hours. I joined the same English club and observed as a non-participant. During the time I noted the environment and the activities of the English clubs, and how the participants engaged in the English activities. After that I asked two of the student coordinators from the English club to explore more about how they conduct their out-of-class English learning. I followed them, like their shadows, to document more about their out-of-class English learning. I used a small notebook to record observations to prevent distractions. After each observation, I wrote field notes immediately to put my experience into text (Emerson, Fretz \& Shaw, 1995). The field notes were later expanded for analysis. It should be noted that the expanded field notes were not like a mirror of what happened, but they were influenced by my background.

To supplement the observations and interviews, informal questions were asked to gathered relevant information from the participants which includes a brief autobiography and various reflections on education, culture, and English learning experience. In these instances, notes were taken of the participants' experience and perspectives of out-of-class English learning.

\subsection{Data analysis and trustworthiness}

An inductive approach is at the heart of the data analysis in this research. Charmaz and Mitchell (2001) describes the inductive approach as a method in which "you start with individual cases, incidents, or experiences and develop progressively more abstract conceptual categories to synthesize, to explain and to understand your data and to identify patterned relationships within it" (p. 335). Such a method involves the inductive creation of codes or themes giving rise to emerging theory; these are then constantly compared with the data in a process of continual refinement (Strauss \& Corbin, 1998).

Before analyzing the data, Prabjandee (2019) suggested checking the quality of the data. In this study, the interviews were transcribed professionally, and I rechecked the accuracy of the transcripts. The quality of the observation notes was also examined. Once I maximized the quality of the data, I started analyzing the data by reading and rereading them. I also listened to the tape recordings numerous times and wrote down any impressions about socio-cultural factors that I encountered. These impressions were useful when identifying themes. The data were analyzed vertically (within-case) and horizontally (cross-case) (Merriam, 2009). For the vertical analysis, I analyzed the entire set of the data within the individual student by using the coding method, consisting of three analysis stages: (1) open coding, (2) axial coding, and (3) selective coding (Saldaña, 2009; Prabjandee, 2019).

In the open coding stage where the aim was to assign codes to the data with no prior frameworks, I identified initial codes. Based on the frequency of the answers, some examples of the codes were "friendly partners," "friendship," "teamwork," "new knowledge and experiences," "communication skills," "excitement and relaxation," "cultural environment," etc. In the axial coding stage, I reexamined the open codes and identified the relationships among them to generate categories. In the selective coding stage, I combined the categories into themes by selectively choosing the ones related to socio-cultural factors influencing out-of-class learning. Finally, the results of the vertically three-stage analysis were compared horizontally across cases to examine similarities and differences in learners' out-of-class English learning. Besides, the themes were arranged by the frequency of the participants' answers to make a distinction. To maximize the trustworthiness of the analysis, I kept writing reflections to be aware of my subjectivity (Prabjandee, 2019). The reflections were used during the analysis to question the interpretation of the data. were used during the analysis to question the interpretation of the data. 
Table 1: The thematic data analysis

\begin{tabular}{|c|c|c|}
\hline Codes & Categories & Themes \\
\hline $\begin{array}{ll} & \text { Get along with each other } \\
\text { - } & \text { Many people together } \\
\text { - } & \text { Friendly friends } \\
\text { - } & \text { Talk about anything with each other } \\
\text { - } & \text { Encouragement from friends } \\
\text { - } & \text { Inspiration from interesting friends } \\
& \text { Help and support with English from friends }\end{array}$ & Supportive peers & $\begin{array}{l}\text { Peers influence out-of- } \\
\text { class English learning }\end{array}$ \\
\hline $\begin{array}{ll}\text { - } & \text { Careless partners } \\
\text { - } & \text { Annoying classmates } \\
\text { - } & \text { Noisy students } \\
\text { - } & \text { Too crowded, many people } \\
\text { - } & \text { Partners fear to speak slowly or fault, always keep } \\
& \text { silent }\end{array}$ & Discouraging peers & \\
\hline $\begin{array}{ll}- & \text { Enrich vocabulary } \\
\text { - } & \text { English speaking ability improvement } \\
\text { - } & \text { Better English expression } \\
\text { - } & \text { The Fluency of English }\end{array}$ & $\begin{array}{l}\text { English competence } \\
\text { improvement }\end{array}$ & $\begin{array}{l}\text { Benefits of out-of-class } \\
\text { English learning }\end{array}$ \\
\hline $\begin{array}{ll}\text { - } & \text { Learning skills improvement } \\
\text { - } & \text { Get more experience } \\
\text { - } & \text { Learned different nationalities festivals and historical } \\
\text { - } & \text { Make good use of high technology } \\
\text { - } & \text { Get more knowledge } \\
\text { - } & \text { To know more cultures of other countries } \\
\text { - } & \text { Cocial skills } \\
\text { - } & \text { Learnection with outside the world } \\
\text { - Skills to organize activities }\end{array}$ & $\begin{array}{l}\text { Other knowledge and } \\
\text { skills gained from } \\
\text { out-of-class English } \\
\text { learning }\end{array}$ & \\
\hline $\begin{array}{ll}\text { - } & \text { Become braver } \\
\text { - } & \text { Be more outgoing } \\
\text { - } & \text { Be confident and cheerful } \\
\text { - } & \text { Stronger heart } \\
\text { - } & \text { Made more friends } \\
\text { - } & \text { Deanged with weople well }\end{array}$ & Self-improvement & \\
\hline $\begin{array}{ll}\text { - } & \text { Enjoy } \\
\text { - } & \text { Excitement } \\
\text { - } & \text { Relax } \\
\text { - } & \text { Cool, awesome } \\
\text { - } & \text { Happy } \\
\text { - } & \text { Funny } \\
\text { - } & \text { Interesting } \\
\text { - } & \text { Unforgettable experience } \\
\end{array}$ & $\begin{array}{l}\text { Positive atmosphere } \\
\text { response to the out- } \\
\text { of-class English } \\
\text { learning }\end{array}$ & $\begin{array}{l}\text { Environment } \\
\text { influences out-of-class } \\
\text { English learning }\end{array}$ \\
\hline $\begin{array}{ll}\text { - } & \text { Foreign cultural environment } \\
\text { - } & \text { Challenging } \\
\text { - } & \text { More active thinking. } \\
\text { - } & \text { You must improve, so you improved } \\
\end{array}$ & $\begin{array}{l}\text { The power and } \\
\text { specialty of the out- } \\
\text { of-class English } \\
\text { learning environment }\end{array}$ & \\
\hline - $\quad$ Sometimes too noisy & $\begin{array}{l}\text { Negative emotional } \\
\text { response to the } \\
\text { environment }\end{array}$ & \\
\hline $\begin{array}{ll}- & \text { Play games } \\
- & \text { Communication }\end{array}$ & $\begin{array}{l}\text { Various out-of-class } \\
\text { English activities }\end{array}$ & $\begin{array}{l}\text { The quality of English } \\
\text { club activities }\end{array}$ \\
\hline
\end{tabular}




\begin{tabular}{lll}
\hline - & English exercises & \\
- & Discussions & \\
- & Presentations & \\
- & Group activities & \\
\hline - & Try new things & Compare to the in- \\
- & To learn something, you can't learn in class & $\begin{array}{l}\text { class English learning } \\
\text { activities }\end{array}$ \\
\hline - & Bharing interesting things & $\begin{array}{l}\text { Negative emotional } \\
\text { response to the } \\
\text { activities }\end{array}$
\end{tabular}

\section{Findings}

Out-of-class English is good for the students to learn English, it creates good English-speaking environment and opportunities to practice English. It also can help students to get more knowledge of culture, technology and even friendship. Out-of-class English learning also help them became a better self. This study explored and found that cultural atmosphere, activities, benefits and friends have influence on out-of-class English learning, study also found that friends have a major influence Chinese students' out-of-class English.

The first factor was peers. This factor is the most frequently reported socio-cultural factor that this study revealed. For the participants, peers refer to the other students in the English club, who have tremendous influence on their English learning. The participants reported types of peers that had positive influence and negative influence on their out-of-class English learning. The factor peers give inspirations and encouragements to others, they affect the learners' attitudes and motivations of out-of-class English learning. On the other hand, the English ability, skills and personality of friends have great influence on learners. Some excellent learners inspired other learners on English learning. What's more, students focused on not only language itself but also the relationship with friends. They thought that learning in the club is a good teamwork, the out-of-class activities provide more interactions of English speaking and friendship. There are always communications, co operations, friendly relationships and team works in out-of-class English learning. However, the silient or inactive partners may make the learners discourage on out-of-class English activities, they became unwilling to speak out or interact with others.

The second factor was benefits. Learners thought that out-of-class English not only help them improved their oral English, communication skills but also knowledge, experiences and even self-improvement. Out-of-class English learning such as English club provides language environment, speaking opportunities to practice especially speaking, listening and communication skills, new vocabularies, new expressions and new things. Knowledge and experiences from out-of-class English learning are another part of benefit that make students enjoy learning English outside the classroom, such as culture, social problems and make good use of high technology, etc. What's more, it is meaningful in the way of students' self- improvement by the way of being more confident, have better expressions and methods of learning and life. Interestingly, English club as an out-of-class English learning activity is meaningful in the way of students' self- improvement. English club made them more confident than before. Beyond English language, students found themselves changed or became a better self.

The third factor was language environment. The results show that the English language environment plays an important role in out-of-class English learning. Students enjoy the relaxing, friendly language atmosphere. Outof-class English learning is not as serious as in the class so that students may be able to have more active and wider thoughts. It's different from "teacher-centered" English learning which usually takes in the class. Students can talk freely with anyone in out-of-class English learning. Students explained that the environment of out-of-class English learning was friendly, because there were a number of friendly partners to communicate with. Interestingly, students in the language environment, example an English club, are supposed to speak only English by default. In such an English peaking environment, students had to learn to understand more English in order to interact with each other well. In other words, the environment "force" them to speak out, to improve their English in order to get along with others. For some students, their English were improved because of the English-speaking environment, as they had to speak out.The study also found that the foreign cultural environments from English native speakers is a boost and efficient way to improve their English with deeper understanding of western culture and followed by English language listening, pronunciation and communication skills. However, the noisy or silent environment could also make students feel uncomfortable or unwilling to speak out and cannot engage the activities well.

The fourth factor was the quelity of English club activities. Compare to the in-class activities which is full of writing and listening. Learners prefer interesting and friendly out-of-class English learning activities which engaged by groups or teamwork such as, games, plays, presentations, speeches, interviews, dubbing competitions, discussions, competitions, experience sharing and activities of management, etc. When they engage English lucb 
activities, they are willing and enjoy talking with each other and change our feeling with each other. In addition, the activities in this study are more about "social-directed naturalistic learning" which engaged by groups or teamwork, created a variety of English language resources, inputs and opportunities to lean something different with in-class English learning. Students thought they hardly ever have good activities to practice speaking when in learning in class. Out-of-class English group activities are more attractive to students.

In order to explore more in-depth and richer information. I describe two individual cases which conducted both interview and observation, too. The individual narratives below reflect their perspectives and experience of out-of-class English learning.

\section{Yang's Case}

Having formed an overall understanding of the out-of-class English learning processes and themes of year one Chinese university students I explored a special perspective of Yang, a student in charge of an out-of-class English learning activity. After I followed and observed his personal life. I noted that Yang is an English lover, that is the reason he organizes the English club in university. He is happy to meet more people who love English, then he could learn and practice English with them together. After class, he likes to join other English activities. He said: "That's a good opportunity to really practice English". He told me that learning English needs to do more practice, no matter where and when. He also introduced his friends to me, two of them are from America and Thailand. They often sit together and chat with each other in English. In his opinion, real English practice needs to be done with people, not just with a book or internet, a good partner can teach us so much.

Yang holds a new and interesting group - English Dubbing Club - which I joined and observed. I found the crucial aspect involves cooperation and teamwork with partners in the out-of-class activities. There were four different groups in the club he holds, they were hosts, competitors, audiences and judges. In an environment where learners practice English by talking together, doing activities, they do their own duties but also interact with each other well. As his quote below, English corners provides learners a friendly and abundant language communication environment:

This club will hold some English corners, each time, there will be some friends from foreign countries they will come here and we will talk together, communicate with each other.

The competitors dubbed the video with partners or individually. Least or most, learners interacted with partners and acquired not only English practice and improvement but also friendship and spirit of teamwork. In more depth to understand out-of-class English learning experiences, Yang explained his perspective of English club activity:

I think it is brilliant, because learning in the club is good teamwork.

Despite friendship and teamwork of what he mainly mentioned through English club, he also was interested in the way of communication and the information. Yang's English language ability is strong, but he feels that the benefits of out-of-class English learning are not just about English language but also self-improvement and sociability. It is crucial to build self-improvement such as confidence in English learning, hence learners should be encouraged to speak English and engage more activities to practice English.

It teaches me how to deal with people, how to communicate with people in a right way. You can learn how to get the information that you want...I can make some friends, when I need help, they will give me a hand.

The central points that he recognized about English club are all related to "people", partners gather together and share their experience both in study and life in English, they gained not only English language skills but also friendship and some other skills like good methods of learning and life experience.

I like the people there. Different people from different provinces, and different areas, we come here, together. And we share a lot both in life and our study. We learn a lot (of) things from each other. First of all, we can get to know more people. What's more, we can share some methods, and learn how to improve English. Also, some of them, some the partners here are excellent, I learn a lot from them, some skills, some of them are outgoing, they have some good influence on me.

\section{Wan's Case}

Compared with Yang, Wan talked more about the environment and benefits of the English club. Wan was born in the eastern coastal areas of China. She can speak English fluently; one important factor is because of the environment where she lived. Her hometown is full of famous tourism resources, where she could meet and speak English to people from other countries. She believed that language environment is necessary for all English learners. Therefore, she tried to create the "environment"- English club. She has an in-depth opinion about culture and politics. She thought that English club is a place where people talk with each other in a foreign language, it is also a place where people can learn something about foreign culture. She shared her English learning methods and experience with other partners, and she explained that English learning should not be limited to language learning, but also the point of the world and other knowledge. Other partners were quite interested in her "cultural shock" 
stories (as observed when we in the English club).

I think in the club we talk with each other in a foreign language, and we can learn a lot, not only learning skills about English, but also some cultures and some specific issues about a foreign culture.

The reason why she likes the club was because of the language environment. When she interacts with Chinese or foreign partners, the English-speaking circumstances was what she wants. English improvement could happen between talking and interaction with others in Engish.

I think I like the club because of the environment which can provide us a kind of foreign cultural

environment. In this specific environment we can not only talk but also interact with each other.

For the language aspect, English club could help her improve her language skills. That's means with the help of the activities and peers in out-of-class practices, her language skills could be improved. These important "helps" serve as social functions, master learners' language skills. For instance, she mentioned: "If we want to communicate well, we should acknowledge the communicate skills. That's important when we get along with each other in a foreign language".

(The club) ...can help us improve our oral English not only learning reading and writing skills, but also speaking skills. I think that's important. (Wan)

On the other hand, not just language skills got influenced, but also the perspectives of life experiences and knowledge of foreign culture, foreign politics are impacted through out-of-class English learning. She emphasized,

I think the club teaches me, you know, for language learning, you know, listening, speaking, writing and reading, these skills are very important, but you should have kind of view about the, you know, foreign culture, foreign politics, yeah, about foreign language, your attention should not only be put on the language itself, but also all kind of things. (Wan)

\section{Dissscusion}

Out-of-class English learning is an essential part of language learning. It is necessary for advanced language learning because the amount of language exposure associated with formal classes was not enough. No matter how good classes might have been, most learner felt that they were not enough, they accept out-of-class learning as a personal responsibility. Therefore, to do out-of-class English learning, how to have good out-of-class English learning and to know what factors influence out-of-class is necessary (Blyth \& LaCroix-Dalluhn, 2011; Stickler \& Emke, 2011).

According to the findings of this research question. This study explored and found four socio-cultural factors mainly influenced Chinese learners' out-of-class English learning. Which proved the SCT by Vygotsky (1962), and also agreed with the results of previous studies (Pearson, 2004; Ozfidan, Machtmes \& Demir, 2014; Krause \& Duchesne, 2000). They are social cultural environments, out-of-class activities, benefits of out-of-class English learning and friends. These factors proved the findings of previous studies. They positively and negatively influence learners' out-of-class English learning.

\subsection{Sociocultural Theory}

Vygotsky (1962) pointed out that second language learning comes out from cultural and social activity and only later becomes reconstructed as an individual, psychological phenomenon. It means that learning and development are grounded in interactions with the outside world. Therefore, any investigation of learning development should include socio-cultural aspects of learning, such as social interactions, artifacts, cultural conditions and tools. Accordingly, some essential cultural and social factors are believed to organize human psychological processes: activities (e.g. education), artifacts (. e.g. books, paper, technology, language...etc.) and concepts (e.g. knowledge of the world) (Lantolf, 2006).

This study fully agrees with the SCT by Vygotsky (1962). As an essential part of second language learning, out-of-class English learning is more influenced by the cultural and social aspects compare to in-class English learning. This study found that when learners practice and learn English outside the classroom, especially when learners join the group activities, such as English club, English Camp and English competitions, the good language environment and friendly atmosphere make learners willing to speak out and be open-minded to interact with others. Activities decide whether learners could understand language and practice it well. Once they meet new words which they do not know, they can ask for help from dictionaries or friends and teachers. After that, the new words, knowledge, experiences, English abilities were reconstructed by learners as an individual as benefits.

More specifically, while participating in a particular out-of-class English activity, learners used certain formats and routines taught by teachers, parents or peers (Bruner, 1985). In order to communicate with others in the activity, they would have to speak out and keep learning new things, when they meet difficulties, they also have to resort to didactical materials offered by artifacts, such as books and technology. During this period, good atmosphere, effective activities, friends and teachers directly influence learners' willing and motivation of learning English. Then, as the learners develop their language ability, they internalize these formats and routines, using them in other situations. 
Alternatively, good out-of-class learning experiences give learners more and different English formats and routines before they go to class. Out-of-class English learning provides variety activities and opportunities to practice and to learn English, after that, learners could get more language inputs to use in class. Even though the learners of the study were undergraduates, the findings were consistent with theory and former study which were conducted with children in specific contexts (Bruner, 1985).

\subsection{Peers in English Club Influences Out-of-class English Learning}

Peer interaction has a major influence on the language learning process of most of the participants whereas it has a minor influence for few participants (Ozfidan, Machtmes \& Demir, 2014). Peers in the out-of-class English can give learners encouragement to speak out, friends are the helpers when they don't understand the language or the activities (Vygotsky, 1962), excellent friends also inspire learners on English learning. Social interaction with peers is positively related to the quality of student effort and in turn, satisfaction, learning and persistence (Krause, 2005; Tinto, 1987). The negative aspect of out-of-class English is impacted by people around them in the club mostly. As above proved, the friendly and warm partners make learners willing to speak English out and engage the activities, the partners can support them on language and spirit part. However, the silient or inactive partners may make the learners discourage on out-of-class English activities, they became unwilling to speak out or interact with others.

\subsection{Benefits From the English Club Influence Out-of-class English Learning}

Learners agreed that out-of-class English learning gave them abundant benefits. The out-of-class English learning supports learners being involved in real contexts of language practicing. As being a necessary part of second language learning, out-of-class English learning also illustrates prominent examples of not only the language itself, but also expression, and self-development, etc. Out-of-class English learning fosters students to be more competent in the language field.

\subsection{Environment in English Club Influences Out-of-class English Learning}

In this study, the learners believed that good atmosphere raise their motivation and provides better opportunities of English learning. Pearson (2004) also indicated that the living context directly impact learners' social and affective needs and preferred learning style. He found that Chinese students in New Zealand who lived in university hostels, for example, were less inclined towards spending time on personal writing and less likely to have native speakers as friends. On the other hand, Pearson indicated that students who lived in homestays, were more likely to use English at home naturally and less inclined to spend time talking or working with other students learning English. Furthermore, the cultural environment guides learners to access the cultural realities and realize own and western cultures, it is attractive and also good for learners to have better understanding on English learning, and it may boost the motivation of learners or make learner open their mouth to express themselves by English. On the other hand, the noisy and annoying environment discouraging learners out-of-class English learning.

\subsection{The Quality of English Club Activities}

On the other hand, learners were interested in out-of-class English activities, because these activities provided more opportunities to practice or interact with partners and teachers. Interesting activities help learners practice English effectively and have a better understanding of English language. Teamwork and group activities are positive learning experiences to students, they drive students' interest and motivation on out-of-class English learning (Li, Clarke, \& Remedios, 2010). As a study explained, in the first-year experience, particularly, friendship networks are a key to successful adjustment (Krause \& Duchesne, 2000). However, the repeated and outmoded out-of-class English activities negativly impacted learners' out-of-class English learing.

\section{Conclusion}

This study offers an insight into the process of out-of-class English learning. It was revealed that out-of-class English learning was influenced by peers,benefits, environment, and the quality of activities. Teachers in China should pay careful attention to the out-of-class English learning, especially sharing some out-of-class English learning experiences, individual cases, learning methods and resources with learners; or applying some good activities from out-of-class English leaning into school and class. Future research may examine how to make learners have good and effective out-of-class English learning.

\section{References}

Benson, P. (2001). Teaching and researching autonomy in language learning. Harlow, England: Longman. http://dx.doi.org/10.1057/9780230306790

Benson, P., \&Reinders, H. (2011). Introduction. In P. Benson \& H. Reinders (Eds.), Beyond the language classroom (pp. 1-6). New York, NY: Palgrave Macmillan. 
Blyth, D. A., \&LaCroix-Dalluhn, L. (2011). Expanded learning time and opportunities: Key principles, driving perspectives, and major challenges. New Directions for Youth Development, 131, 15-27. doi:10.1002/yd.405

Bruner, J. (1985). Child's talk: Learning to use language. Child Language Teaching and Therapy, 1(1), 111-114.

Butler, Y. G. (2011). The implementation of communicative and task-based language teaching in the Asia-Pacific region. Annual Review of Applied Linguistics, 31, 36-57. doi:10.107/S0267190511000122

Charmaz, K., \& Mitchell, R. G. (2001). Grounded theory in ethnography. Handbook of ethnography, 160, 174.

Emerson, R. M., Fretz, R. I., \& Shaw, L. L. (1995). Fieldnotes in ethnographic research. Writing ethnographic fieldnotes, 1-16.

Field, J. (2007). Looking outwards, not inwards. ELT Journal, 61(1), 30-38

Hyland, F. (2004). Learning autonomously: Contextualising out-of-class English language learning. Language Awareness, 13(3), 180-202. doi:10.1080/09658410408667094

Inozu, J., Sahinkarakas, S., \& Yumru, H. (2010). The nature of language learning experiences beyond the classroom and its learning outcomes. US-China Foreign Language, 8(1), 14-21.

Kirkpatrick, R., \& Zang, Y. (2011). The negative influences of exam-oriented education on Chinese high school students: Backwash from classroom to child. Language testing in Asia, 1(3), 36.

Krause, K., (2005), Serious thoughts about dropping out in first year: Trends, patterns and implications for higher education. Studies in Learning, Evaluation, Innovation and Development, 2(3): 5567.(http://sleid.cqu.edu.au/)

Krause, K., \& Duchesne, S., (2000), With a little help from my friends: Social interactions on campus and their role in the first year experience. Paper presented at the Fourth Pacific Rim Conference: First Year in Higher Education-Creating futures for a new millennium, 5-7 July, Brisbane, Australia.

Lantolf, J. P. (2006). Sociocultural theory and the genesis of second language development.

Li, D., Clarke, D., \& Remedios, L. (2010). Chinese students' perception of out-of-class groupwork in Australia. The Australian Educational Researcher, 37(3), 95-112.

Merriam, S. B. (2009). Qualitative research: A guide to design and implementation. San Francisco: Jossey-Bass.

Ozfidan, B., Machtmes, K. L.,\& Demir, H. (2014). Socio-Cultural Factors in Second Language Learning: A Case Study of Adventurous Adult Language Learners. European Journal of Educational Research. Vol. 3, No. 4, 185-191).

Pan, L., \& Block, D. (2011). English as a "global language" in China: An investigation into learners' and teachers' language beliefs. System, 39, 391-402. doi:10. 1016/j.system.2011.07.011

Pearson, N. (2004). The idiosyncrasies of out-of-class language learning: A study of mainland Chinese students studying English at tertiary level in New Zealand. In Proceedings of the Independent Learning Conference 2003. Paper presented at the Independent Learning Conference, University of Melborne, Melbourne, 13-14 September, 2003.

Prabjandee, D. (2019). Becoming English teachers in Thailand: Student teacher identity development during teaching practicum. Issues in Educational Research, 29(4), 1277-1294.

Saldaña, J. (2009). The coding manual for qualitative researchers. Thousand Oaks, CA: SAGE.

Song, M. (2013). Participant perceptions about speaking and listening in modern foreign language classes in China and England, and their relationship to classroom practices. (Doctoral dissertation, University of Warwick).

Stickler, U., \&Emke, M. (2011). Tandem learning in virtual spaces: Supporting non-formal and informal learning in adults. In P. Benson \& H. Reinders (Eds.), Beyond the language classroom: The theory and practice of informal language learning and teaching (pp. 146-160). Palgrave Macmillan, London.

Strauss, A., \& Corbin, J. (1998). Basics in qualitative research. Thousand Oaks, CA: Sage.

Tinto, V. (1987). Leaving college: Rethinking the causes and cures of student attrition. University of Chicago Press, 5801 S. Ellis Avenue, Chicago, IL 60637.

Vygotsky, L.S. (1962). Thought and Language. Cambridge, MA: MIT Press.

Vygotsky, L. S.(1978). Interaction between learning and development. Readings on the development of children, 23(3), 34-41.

Wolcott, H. F. (2003). The man in the principal's office: An ethnography. Walnut Creek, CA: AltaMira Press. 